\title{
A realist partner for Linda: confirming a theoretical hypothesis more than its observational sub-hypothesis
}

\author{
Theo A. F. Kuipers
}

Received: 1 July 2009 / Accepted: 9 November 2009 / Published online: 5 December 2009

C The Author(s) 2009. This article is published with open access at Springerlink.com

\begin{abstract}
It is argued that the conjunction effect has a disjunctive analog of strong interest for the realism-antirealism debate. It is possible that a proper theory is more confirmed than its (more probable) observational sub-theory and hence than the latter's disjunctive equivalent, i.e., the disjunction of all proper theories that are empirically equivalent to the given one. This is illustrated by a toy model.
\end{abstract}

Keywords Linda-effect - Conjunction-effect - Disjunction-effect .

Confirmation - Realism-antirealism debate

\section{Introduction}

The Linda- or conjunction-effect is a case in which a stronger hypothesis is, though less probable, more confirmed than a weaker consequence. This is good news for epistemological realists for they may have the feeling that a theoretical hypothesis, though less probable than its (strongest) observational sub-hypothesis, can be more confirmed. The purpose of this paper is to show first, by way of (some variations of) a toy model, that this is possible in the form of a disjunction effect and second that it in these cases by and large a robust effect of all major degrees of confirmation in debate. The latter is the more impressive the more one subscribes to the view that there is not one best confirmation language, but that different ones may serve different purposes beyond some robust features. The former, a toy model, asks of course for real life scientific examples, preferably including some not only with theoretical properties as in the toy model, but also with theoretical entities.

T. A. F. Kuipers $(\varangle)$

Platanenlaan 15, 2061 TP Bloemendaal, The Netherlands

e-mail: T.A.F.Kuipers@rug.nl 
The main part of this paper consists of some formal cases and corresponding toy examples. The paper concludes with some suggestions for the search of realistic examples.

\section{Some formal cases and corresponding toy examples}

\subsection{First case}

Let hypotheses $\mathrm{h} 1$ and $\mathrm{h} 2$ be incompatible and let evidence e be such that $\mathrm{P}(\mathrm{h} 1 \wedge$ $\neg \mathrm{h} 2 \wedge \mathrm{e})=1 / 6+\varepsilon(0<\varepsilon<1 / 6)$ and $\mathrm{P}(\neg \mathrm{h} 1 \wedge \mathrm{h} 2 \wedge \mathrm{e})=1 / 6-\varepsilon$, whereas all remaining four compatible triples get probability $1 / 6$. See Fig. 1 (Sect. 5) of the paper by Atkinson (2010) for a useful Venn-diagram, reproduced in adapted form at the beginning of Appendix 1.

Let $\mathrm{f}$ be the disjunctive hypothesis $\mathrm{h} 1 \vee \mathrm{h} 2$. In an appropriate interpretation, see the die example below, this may be such that $\mathrm{f}$ is the observational sub-hypothesis (the strongest observational consequence) of h1 as well as of h2, both of which are assumed to be theoretical. Hence, h1 and h2 are then observationally equivalent (in the strong, logical sense, that is, whatever the evidence is). Note that $\mathrm{f}$ is of course (a priori as well as a posteriori) more probable than both $\mathrm{h} 1$ and $\mathrm{h} 2$. Moreover, according to the assigned probabilities, $\mathrm{p}(\mathrm{h} 1)=1 / 3+\varepsilon>\mathrm{p}(\mathrm{h} 2)=1 / 3-\varepsilon$.

Let 'B-confirmation' be short for confirmation according to Bayesian confirmation (c-)measures, that is, $\mathrm{c}$-measures that have $\mathrm{c}(\mathrm{h}, \mathrm{e})>0$ for (probabilistic) confirmation, i.e. $\mathrm{p}(\mathrm{h} \mid \mathrm{e})>\mathrm{p}(\mathrm{h}), \mathrm{c}(\mathrm{h}, \mathrm{e})<0$ for disconfirmation $(\mathrm{p}(\mathrm{h} \mid \mathrm{e})<\mathrm{p}(\mathrm{h}))$ and $\mathrm{c}(\mathrm{h}, \mathrm{e})=0$ for neutral evidence $(\mathrm{p}(\mathrm{h} \mid \mathrm{e})=\mathrm{p}(\mathrm{h}))$. All $10 \mathrm{c}$-measures considered in this paper, that is, the 9 measures dealt with in Atkinson et al. (2009, see pp. 4-5 for a list of them, see also Appendix 1) and the new (confirmation cum justification) measure put forward by Shogenji (2010), viz. J(h, e) $=1-[\log \mathrm{p}(\mathrm{hle}) / \log \mathrm{p}(\mathrm{h})]$, are Bayesian.

Claim 1 e B-confirms h1 more than f, to which it is B-neutral. Moreover, e B-disconfirms h2. That is, $\mathrm{c}(\mathrm{h} 1, \mathrm{e})>\mathrm{c}(\mathrm{f}, \mathrm{e})=0>\mathrm{c}(\mathrm{h} 2$, e) holds for all Bayesian c-measures.

Proof we only need to prove: $\mathrm{p}(\mathrm{h} 1 \mid \mathrm{e})>\mathrm{p}(\mathrm{h} 1), \mathrm{p}(\mathrm{f} \mid \mathrm{e})=\mathrm{p}(\mathrm{f})$, and $\mathrm{p}(\mathrm{h} 2 \mid \mathrm{e})<\mathrm{p}(\mathrm{h} 2)$. These three claims are easy to prove.

Assuming the occasional defensibility of the observable and theoretical status of the hypotheses, respectively, we may conclude that e B-confirms theoretical hypothesis h1 more than its disjunctive observational sub-hypothesis $\mathrm{f}$, which on its turn is B-confirmed more than theoretical hypothesis h2. Hence, by transitivity, e B-confirms theoretical hypothesis h1 more than its observationally equivalent theoretical hypothesis h2. The following die example realizes the type of hypotheses suggested.

Example Let a die be loaded in favor of (face) 6 and in equal disfavor of 4 . It is fair with respect to $1,2,3$, and 5 . Let h1 correspond to the outcome 1 or 6 , and h2 to the outcome 3 or 4 (and h3 to the outcome 5 or 2 ). In sum, let there be $\varepsilon(0<\varepsilon<1 / 6)$ such that $\mathrm{p}(6)=1 / 6+\varepsilon, \mathrm{p}(4)=1 / 6-\varepsilon$, and $\mathrm{p}(1)=\mathrm{p}(2)=\mathrm{p}(3)=\mathrm{p}(5)=1 / 6$. However, 
let the faces $1,3,4,6$ not be directly observable but hidden by stickers. On the faces 1 and 3 the sticker is telling $1 \mathrm{v} 3$ and on the faces 4 and 6 it tells $4 \mathrm{v} 6$.

Note that $\mathrm{f}$ now corresponds to the observable outcome $1 \mathrm{v} 3 \mathrm{v} 4 \mathrm{v} 6$. Note also that outcomes even/odd remain observable, despite the stickers. On the other hand, the outcomes $\mathrm{h} 1$ and $\mathrm{h} 2$ are non-observable, they are observationally equivalent, by both having $\mathrm{f}$ as their disjunctive observable sub-hypothesis. In a table, in which $*$ indicates being observable, we get:

\begin{tabular}{lllll}
\hline & $\mathrm{h} 1$ & $\mathrm{~h} 2$ & $\mathrm{f}^{*}$ & $\mathrm{~h} 3^{*}$ \\
\hline Odd $^{*}$ & 1 & 3 & $(1 \text { or } 3)^{*}$ & $5^{*}$ \\
Even* & 6 & 4 & $(4 \text { or } 6)^{*}$ & $2^{*}$ \\
\hline
\end{tabular}

In this example we obtain that an (observable) even outcome B-confirms theoretical hypothesis h1, B-disconfirms theoretical hypothesis h2, and is B-neutral with respect to the disjunctive observable sub-hypothesis $\mathrm{f}$ of both.

\subsection{Second case}

Let $\mathrm{h} 1, \mathrm{~h} 2, \mathrm{f}$ and e be as before, but now such that $\mathrm{P}(\mathrm{h} 1 \wedge \neg \mathrm{h} 2 \wedge \mathrm{e})=\mathrm{z}>1 / 6$, whereas all remaining five compatible triples have equal probability, hence $(1-z) / 5$, which is smaller than $1 / 6$. In terms of the die example we get: $p(6)=z>1 / 6$, $\mathrm{p}(1)=\mathrm{p}(2)=\mathrm{p}(3)=\mathrm{p}(4)=\mathrm{p}(5)=(1-\mathrm{z}) / 5={ }_{\mathrm{df}} \mathrm{u}(<1 / 6)$. Hence, the die is loaded in favor of 6 and in equally spread disfavor of all other five faces.

Claim 2.1 e B-confirms $\mathrm{h} 1$ and $\mathrm{f}$ and e B-disconfirms h2. That is, $\min \{\mathrm{c}(\mathrm{h} 1, \mathrm{e}), \mathrm{c}(\mathrm{f}$, e) $\}>0>\mathrm{c}(\mathrm{h} 2, \mathrm{e})\}$ holds for all Bayesian c-measures.

Claim 2.2 e confirms h1 more than $\mathrm{f}$ according to all 9 measures treated in Atkinson et al. (2009), except Z(h,e). That is, c(h1, e) > c(f,e) holds for all these measures, except for $\mathrm{Z}(\mathrm{h}, \mathrm{e})$, in which case $\mathrm{Z}(\mathrm{h} 1, \mathrm{e})=\mathrm{Z}(\mathrm{f}, \mathrm{e})>0$. Moreover, it holds for Shogengji's J-measure.

Proof The first claim is easy to prove. The (analytical) proofs of the second claim with respect to the 9 measures are given in Appendix 1. So far, I did not succeed in finding an analytical proof for the J-measure. However, David Atkinson provided a 'graphic proof', see Appendix 2.

In this example we obtain that an (observable) even outcome confirms, according to all but one of the measures considered, theoretical hypothesis $\mathrm{h} 1$ more than its disjunctive observable sub-hypothesis f.

\subsection{Third case}

Let $\mathrm{h} 1, \mathrm{~h} 2$, $\mathrm{f}$ and e be as before, but now such that for some $\varepsilon, 0<\varepsilon<1 / 6, \mathrm{P}(\mathrm{h} 1 \wedge$ $\neg \mathrm{h} 2 \wedge \mathrm{e})=1 / 6+\varepsilon, \mathrm{P}(\neg \mathrm{h} 1 \wedge \neg \mathrm{h} 2 \wedge \neg \mathrm{e})=1 / 6-\varepsilon$, whereas all remaining four compatible triples have equal probability, i.e. $1 / 6$. In terms of the die example we get: 
$\mathrm{p}(6)=1 / 6+\varepsilon, \mathrm{p}(5)=1 / 6-\varepsilon$, and $\mathrm{p}(1)=\mathrm{p}(2)=\mathrm{p}(3)=\mathrm{p}(4)=1 / 6$ and $\mathrm{p}(1)=\mathrm{p}(2)=\mathrm{p}(3)=\mathrm{p}(4)=1 / 6$. Hence, the die is loaded in favor of 6 , in disfavor of 5 , and fair with respect to the other outcomes. Now we get a claim which is as easy to prove as claim 1 .

Claim 3 e B-confirms h1, while it B-disconfirms $\mathrm{f}$ as well as $\mathrm{h} 2$. That is, $\mathrm{c}(\mathrm{h} 1, \mathrm{e})>0$ $>\max \{\mathrm{c}(\mathrm{f}, \mathrm{e}), \mathrm{c}(\mathrm{h} 2, \mathrm{e})\}$ holds for all Bayesian c-measures.

Hence, e confirms theoretical hypothesis h1 more than its disjunctive observational sub-hypothesis $\mathrm{f}$ and its observationally equivalent $\mathrm{h} 2$. To some extent it is hence a variant of the first example. In that example the disfavor was put on $\mathrm{h} 2$, and hence 'balanced' in the disjunction h1vh2. Now the disfavor is put on h3.

\section{Concluding remarks}

As suggested in the introduction, the fact that a stronger hypothesis can be (robustly) more confirmed than a weaker consequence is very interesting for scientific realists. It suggests that a theory can be more confirmed than its observational sub-theory. Assuming that confirmation of a theory deals with the question whether it is true or false, this is grist to their mill. Take Mendel's theory. It is in principle possible that the evidence of the transmission of observable features in successive generations of organisms can be such that it confirms the full theory of Mendel, with its theoretical entities and properties, more than the conjunction of all observational regularities it implies. Similarly for all other 'proper theories', that is, theories with genuine theoretical terms in addition to terms that are not laden with those theories themselves (See Kuipers 2001, for the theory-relative distinction). The strange thing is that so far I did not succeed in finding claims of this kind in the realism-antirealism debate (Kuipers, to appear).

Additional questions arise when we look at this possibility from the point of view that within a given language any observational theory can be seen as the disjunction of all empirically equivalent (EE-)theories that have the former as their observational sub-theory. Is it possible that more than one of the EE-theories is confirmed more than that sub-theory? If so, the interesting question becomes crucial which one of them is confirmed most. However, none of the three toy examples represents such a situation.

Moreover, so far the relevant notions are all taken in the deductive sense, that is, theories are empirically equivalent when they have the same observational deductive consequences and the observational sub-theory of a theory is the conjunction of all its observational deductive consequences. What happens with these notions when probabilistic consequences (Kuipers 2009) are taken into account is as such already an interesting question, let alone how confirmation of the relevant theories then is related.

Finally, the toy examples in this paper are rather artificial. The hypotheses and hence their prior values do not resemble very much genuine scientific hypotheses and their priors, there are no theoretical entity terms involved, and the theoretical properties are indeed very artificial. However, the toy examples do nevertheless illustrate the principled possibility of scientific cases in which a proper theory is robustly more confirmed than its observational sub-theory. 


\section{Appendix 1: Proof of claim 2.2 with respect to the 9 measures}

\section{in Atkinson et al. (2009)}

We follow the list on pp. 4-5, except that the Z-measure is treated at the end, and start each time with the relevant definition.

To be proven for the remaining 8 measures: $\mathrm{c}(\mathrm{h} 1, \mathrm{e})>\mathrm{c}(\mathrm{f}, \mathrm{e})$

Recall: $\mathrm{P}(\mathrm{h} 1 \wedge \neg \mathrm{h} 2 \wedge \mathrm{e})=\mathrm{z}>1 / 6$, whereas all remaining five compatible triples have equal probability, hence $(1-\mathrm{z}) / 5$. Let $\mathrm{u}$ be $(1-\mathrm{z}) / 5$. Hence, $\mathrm{z}=1-5 \mathrm{u}$, and $\mathrm{u}<\mathrm{z}$. In a figure adapted from Atkinson (2010, Fig. 1, Sect. 5), with the faces of the die in bold, we get:

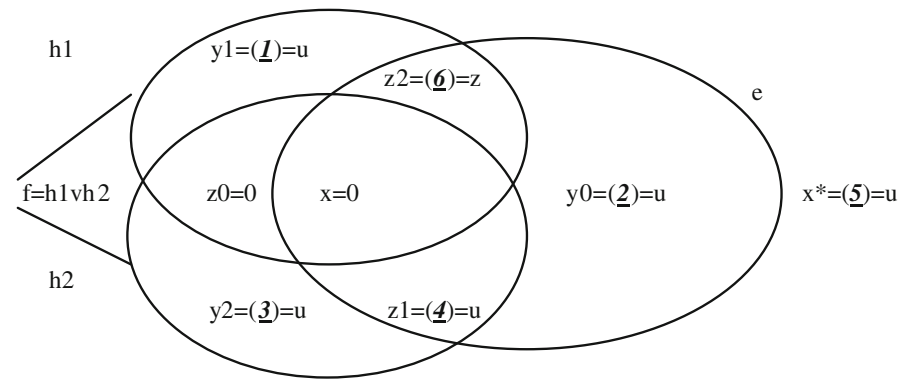

In these variables we have: $\mathrm{z} 0=\mathrm{x}=0, \mathrm{z} 2 \mathrm{df}=\mathrm{z}>1 / 6, \mathrm{z} 1=\mathrm{y} 0=\mathrm{y} 1=\mathrm{y} 2=$ $\mathrm{x}^{*}=(1-\mathrm{z}) / 5=\mathrm{df} \mathrm{u}$.

$$
\mathrm{C}(\mathrm{h}, \mathrm{e})=_{\mathrm{df}} \mathrm{P}(\mathrm{h} \wedge \mathrm{e})-\mathrm{P}(\mathrm{h}) \mathrm{P}(\mathrm{e})
$$

Hence,

$$
\begin{gathered}
\mathrm{C}(\mathrm{h} 1, \mathrm{e})=\mathrm{z}-(\mathrm{z}+\mathrm{u})(\mathrm{z}+2 \mathrm{u})>\mathrm{z}+\mathrm{u}-(\mathrm{z}+3 \mathrm{u})(\mathrm{z}+2 \mathrm{u})=\mathrm{C}(\mathrm{f}, \mathrm{e}) ? \\
2 \mathrm{u}(\mathrm{z}+2 \mathrm{u})>\mathrm{u} ? \\
2 \mathrm{z}+4 \mathrm{u}>1 ? \\
2 \mathrm{z}+4 \mathrm{u}>\mathrm{z}+5 \mathrm{u}=1 \mathrm{OK}
\end{gathered}
$$

Reminder 1: $2 \mathrm{z}+4 \mathrm{u}>1$

$$
\mathrm{D}(\mathrm{h}, \mathrm{e})={ }_{\mathrm{df}} \mathrm{P}(\mathrm{h} \mid \mathrm{e})-\mathrm{P}(\mathrm{h})
$$

Hence,

$$
\begin{gathered}
\mathrm{D}(\mathrm{h} 1, \mathrm{e})=\mathrm{z} /(\mathrm{z}+2 \mathrm{u})-(\mathrm{z}+\mathrm{u})>(\mathrm{z}+\mathrm{u}) /(\mathrm{z}+2 \mathrm{u})-(\mathrm{z}+3 \mathrm{u})=\mathrm{D}(\mathrm{f}, \mathrm{e}) ? \\
2 \mathrm{u}>\mathrm{u} /(\mathrm{z}+2 \mathrm{u}) ? \\
2>1 /(\mathrm{z}+2 \mathrm{u}) ? \\
2 \mathrm{z}+4 \mathrm{u}>10 \mathrm{OK}(\text { Reminder } 1) \\
\mathrm{S}(\mathrm{h}, \mathrm{e})={ }_{\text {df }} \mathrm{P}(\mathrm{h} \mid \mathrm{e})-\mathrm{P}(\mathrm{h} \mid \neg \mathrm{e})
\end{gathered}
$$


Hence,

$$
\begin{gathered}
\mathrm{S}(\mathrm{h} 1, \mathrm{e})=\mathrm{z} /(\mathrm{z}+2 \mathrm{u})-\mathrm{u} / 3 \mathrm{u}>(\mathrm{z}+\mathrm{u}) /(\mathrm{z}+2 \mathrm{u})-2 \mathrm{u} / 3 \mathrm{u}=\mathrm{S}(\mathrm{f}, \mathrm{e}) ? \\
1 / 3>\mathrm{u} /(\mathrm{z}+2 \mathrm{u}) \\
\mathrm{z}+2 \mathrm{u}>3 \mathrm{u} \\
\mathrm{z}>\mathrm{u}(\mathrm{OK})
\end{gathered}
$$

P.M. Z(h, e), see below

$\mathrm{R}(\mathrm{h}, \mathrm{e})={ }_{\mathrm{df}} \log [\mathrm{P}(\mathrm{h} \mid \mathrm{e}) / \mathrm{P}(\mathrm{h})]=\log [\mathrm{P}(\mathrm{e} \mid \mathrm{h}) / \mathrm{P}(\mathrm{e})]$ (assuming non-zero probabilities for $\mathrm{P}(\mathrm{h})$ and $\mathrm{P}(\mathrm{e})$ )

R-comparison amounts to $\mathrm{r}(\mathrm{h}, \mathrm{e})\left({ }_{\mathrm{df}} \mathrm{P}(\mathrm{e} \mid \mathrm{h}) / \mathrm{P}(\mathrm{e})\right)$-comparison, hence $\mathrm{P}(\mathrm{e} \mid \mathrm{h})$ comparison.

Hence,

$$
\begin{aligned}
\mathrm{P}(\mathrm{e} \mid \mathrm{h} 1)=\mathrm{z} /(\mathrm{z}+\mathrm{u}) & >(\mathrm{z}+\mathrm{u}) /(\mathrm{z}+3 \mathrm{u})=\mathrm{P}(\mathrm{e} \mid \mathrm{f}) ? \\
\mathrm{z}(\mathrm{z}+3 \mathrm{u}) & >(\mathrm{z}+\mathrm{u})(\mathrm{z}+\mathrm{u}) ? \\
3 \mathrm{zu} & >2 \mathrm{zu}+\mathrm{uu} ? \\
\mathrm{z} & >\mathrm{u}(\mathrm{OK})
\end{aligned}
$$

Reminder 2: $\mathrm{z}(\mathrm{z}+3 \mathrm{u})>(\mathrm{z}+\mathrm{u})(\mathrm{z}+\mathrm{u})$

$$
\mathrm{L}(\mathrm{h}, \mathrm{e})={ }_{\mathrm{df}} \log [\mathrm{P}(\mathrm{e} \mid \mathrm{h}) / \mathrm{P}(\mathrm{e} \mid \neg \mathrm{h})]
$$

L-comparison amounts to $[\mathrm{P}(\mathrm{e} \mid \mathrm{h}) / \mathrm{P}(\mathrm{e} \mid \neg \mathrm{h})]$-comparison.

Hence,

$$
\begin{gathered}
\mathrm{P}(\mathrm{e} \mid \mathrm{h} 1) / \mathrm{P}(\mathrm{e} \mid \neg \mathrm{h} 1)=[\mathrm{z} /(\mathrm{z}+\mathrm{u})] /[2 \mathrm{u} / 4 \mathrm{u}]>](\mathrm{z}+\mathrm{u}) /(\mathrm{z}+3 \mathrm{u})] /[\mathrm{u} / 2 \mathrm{u}] \\
=\mathrm{P}(\mathrm{e} \mid \mathrm{f}) / \mathrm{P}(\mathrm{e} \mid \neg \mathrm{f}) ? \mathrm{z}(\mathrm{z}+3 \mathrm{u})>(\mathrm{z}+\mathrm{u})(\mathrm{z}+\mathrm{u}) \text { OK }(\text { Reminder } 2) \\
\mathrm{N}(\mathrm{h}, \mathrm{e})=_{\mathrm{df}} \mathrm{P}(\mathrm{e} \mid \mathrm{h})-\mathrm{P}(\mathrm{e} \mid \neg \mathrm{h})
\end{gathered}
$$

Hence,

$$
\begin{gathered}
\mathrm{N}(\mathrm{h} 1, \mathrm{e})=\mathrm{z} /(\mathrm{z}+\mathrm{u})-1 / 2>(\mathrm{z}+\mathrm{u}) /(\mathrm{z}+3 \mathrm{u})-1 / 2=\mathrm{N}(\mathrm{f}, \mathrm{e}) ? \\
\mathrm{z}(\mathrm{z}+3 \mathrm{u})>(\mathrm{z}+\mathrm{u})(\mathrm{z}+\mathrm{u}) \text { OK }(\text { Reminder } 2) \\
\mathrm{K}(\mathrm{h}, \mathrm{e})=_{\mathrm{df}}[\mathrm{P}(\mathrm{e} \mid \mathrm{h})-\mathrm{P}(\mathrm{e} \mid \neg \mathrm{h})] /[\mathrm{P}(\mathrm{e} \mid \mathrm{h})+\mathrm{P}(\mathrm{e} \mid \neg \mathrm{h})]
\end{gathered}
$$

Hence, since $\mathrm{P}(\mathrm{e} \mid \neg \mathrm{h} 1)=1 / 2=\mathrm{P}(\mathrm{e} \mid \neg \mathrm{f})$, the comparison of $\mathrm{K}(\mathrm{h} 1, \mathrm{e})>\mathrm{K}(\mathrm{f}, \mathrm{e})$ ? is of the form

$$
(a-1 / 2) /(a+1 / 2)>(b-1 / 2) /(b+1 / 2)
$$


which holds iff $\mathrm{a}>\mathrm{b}$, and hence, the question is:

$\mathrm{P}(\mathrm{e} \mid \mathrm{h} 1)>\mathrm{P}$ (e|f) OK (see, the R-, that is, r-comparison)

$$
\mathrm{F}(\mathrm{h}, \mathrm{e})=_{\mathrm{df}}[\mathrm{P}(\mathrm{h} \mid \mathrm{e})-\mathrm{P}(\mathrm{h} \mid \neg \mathrm{e})] /[\mathrm{P}(\mathrm{h} \mid \mathrm{e})+\mathrm{P}(\mathrm{h} \mid \neg \mathrm{e})]
$$

Hence,

$$
\begin{aligned}
\mathrm{F}(\mathrm{h} 1, \mathrm{e})= & {[\mathrm{z} /(\mathrm{z}+2 \mathrm{u})-1 / 3] /[\mathrm{z} /(\mathrm{z}+2 \mathrm{u})+1 / 3] } \\
& >[(\mathrm{z}+\mathrm{u}) /(\mathrm{z}+2 \mathrm{u})-2 / 3] /[(\mathrm{z}+\mathrm{u}) /(\mathrm{z}+2 \mathrm{u})+2 / 3]=\mathrm{F}(\mathrm{f}, \mathrm{e}) ? \\
& {[3 \mathrm{z}-(\mathrm{z}+2 \mathrm{u})] /[3 \mathrm{z}+(\mathrm{z}+2 \mathrm{u})] } \\
& >[(\mathrm{z}+\mathrm{u})-2(\mathrm{z}+2 \mathrm{u})] /[(\mathrm{z}+\mathrm{u})+2(\mathrm{z}+2 \mathrm{u})] ? \\
& (2 \mathrm{z}+2 \mathrm{u}) /(4 \mathrm{z}+2 \mathrm{u})>0>(-\mathrm{z}-3 \mathrm{u}) /(3 \mathrm{z}+5 \mathrm{u}) \mathrm{OK} \\
& \mathrm{Z}(\mathrm{h}, \mathrm{e})=_{\mathrm{df}}[\mathrm{P}(\mathrm{h} \mid \mathrm{e})-\mathrm{P}(\mathrm{h})] / \mathrm{P}(\neg \mathrm{h}) \text { if } \mathrm{P}(\mathrm{h} \mid \mathrm{e}) \geq \mathrm{P}(\mathrm{h}) \\
& \mathrm{Z}(\mathrm{h}, \mathrm{e})={ }_{\mathrm{df}}[\mathrm{P}(\mathrm{h} \mid \mathrm{e})-\mathrm{P}(\mathrm{h})] / \mathrm{P}(\mathrm{h}) \text { if } \mathrm{P}(\mathrm{h} \mid \mathrm{e})<\mathrm{P}(\mathrm{h})
\end{aligned}
$$

Hence, $\mathrm{Z}(\mathrm{h}, \mathrm{e})$ depends on whether $\mathrm{h} 1$, resp. $\mathrm{f}$ is confirmed by e; in general amounting to the question $\mathrm{p}(\mathrm{h} / \mathrm{e}) \geq \mathrm{p}(\mathrm{h})$ or, equivalently, $\mathrm{p}(\mathrm{hle}) \geq \mathrm{p}(\mathrm{h} \mid \neg \mathrm{e})$.

$$
\begin{gathered}
\mathrm{P}(\mathrm{h} 1 \mid \mathrm{e})=\mathrm{z} /(\mathrm{z}+2 \mathrm{u})>\mathrm{u} / 3 \mathrm{u}=1 / 3=\mathrm{p}(\mathrm{h} 1 \mid \neg \mathrm{e}) ? \\
3 \mathrm{z}>\mathrm{z}+2 \mathrm{uOK} \\
\mathrm{P}(\mathrm{f} \mid \mathrm{e})=(\mathrm{z}+\mathrm{u}) /(\mathrm{z}+2 \mathrm{u})>2 \mathrm{u} / 3 \mathrm{u}=2 / 3=\mathrm{p}(\mathrm{f} \mid \neg \mathrm{e}) \\
3 \mathrm{z}+3 \mathrm{u}>2 \mathrm{z}+4 \mathrm{u} \text { OK }
\end{gathered}
$$

Hence, since both are confirmed, the question is:

$$
\begin{gathered}
\mathrm{Z}(\mathrm{h} 1, \mathrm{e})=[\mathrm{P}(\mathrm{h} 1 \mid \mathrm{e})-\mathrm{P}(\mathrm{h} 1)] / \mathrm{P}(\neg \mathrm{h} 1)>[\mathrm{P}(\mathrm{f} \mid \mathrm{e})-\mathrm{P}(\mathrm{f})] / \mathrm{P}(\neg \mathrm{f}) ? \\
{[\mathrm{P}(\mathrm{h} 1 \mid \mathrm{e})-\mathrm{P}(\mathrm{h} 1)]>2[\mathrm{P}(\mathrm{f} \mid \mathrm{e})-\mathrm{P}(\mathrm{f})] ?(\operatorname{since} \mathrm{P}(\neg \mathrm{h} 1)=4 \mathrm{u}=2 \mathrm{P}(\neg \mathrm{f}))} \\
{[\mathrm{z} /(\mathrm{z}+2 \mathrm{u})]-(\mathrm{z}+\mathrm{u})>2\{[(\mathrm{z}+\mathrm{u}) /(\mathrm{z}+2 \mathrm{u})]-(\mathrm{z}+3 \mathrm{u})\} ?} \\
[\mathrm{z} /(\mathrm{z}+2 \mathrm{u})]-(\mathrm{z}+\mathrm{u})>(2 \mathrm{z}+2 \mathrm{u}) /(\mathrm{z}+2 \mathrm{u})]-(2 \mathrm{z}+6 \mathrm{u}) ? \\
1=\mathrm{z}+5 \mathrm{u}>(\mathrm{z}+2 \mathrm{u}) /(\mathrm{z}+2 \mathrm{u})=1 ? \text { No }
\end{gathered}
$$

Conclusion: equal confirmation according to $\mathrm{Z}$ !

\section{Appendix 2: Proof of claim 2 with respect to Shogenji's J-measure (with special thanks to David Atkinson)}

$$
\left.\mathrm{J}(\mathrm{h}, \mathrm{e})={ }_{\mathrm{df}} 1-[\log \mathrm{p}(\mathrm{h} \mid \mathrm{e})) / \log \mathrm{p}(\mathrm{h})\right]
$$

For the given values $\mathrm{z}_{0}=\mathrm{x}=0$ and $\mathrm{z}_{1}=\mathrm{y}_{0}=\mathrm{y}_{1}=\mathrm{y}_{2}=\mathrm{x}^{*}=\mathrm{u}$ and $\mathrm{z}_{2}=1-5 \mathrm{u}$, the question is: 


$$
\begin{aligned}
\mathrm{J}\left(\mathrm{h}_{1}, \mathrm{e}\right)= & 1-[\log (1-5 \mathrm{u})-\log (1-3 \mathrm{u})] / \log (1-4 \mathrm{u}) \\
& >1-[\log (1-4 \mathrm{u})-\log (1-3 \mathrm{u})] / \log (1-2 \mathrm{u})=\mathrm{J}\left(\mathrm{h}_{1} \mathrm{vh}_{2}, \mathrm{e}\right) ?
\end{aligned}
$$

The allowed range is $0<\mathrm{u}<1 / 6$, corresponding to $1 / 6<\mathrm{z}_{2}<1$. In the following graph (obtained by the program Mathematica) we see $\mathrm{J}\left(\mathrm{h}_{1}, \mathrm{e}\right.$ ) (solid curve) and $\mathrm{J}\left(\mathrm{h}_{1} \mathrm{v} \mathrm{h}_{2}, \mathrm{e}\right)$ (dashed curve)

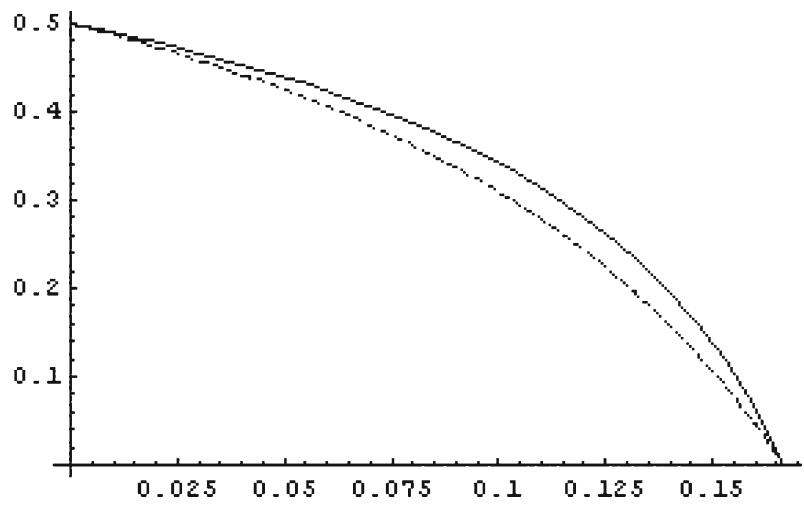

From these curves it can be seen that $J\left(h_{1}, e\right)>J\left(h_{1} v h_{2}\right.$, e) for $0<u<1 / 6$. The difference, $\mathrm{J}\left(\mathrm{h}_{1}, \mathrm{e}\right)-\mathrm{J}\left(\mathrm{h}_{1} \mathrm{v} \mathrm{h}_{2}, \mathrm{e}\right)$, is shown in the following, even more telling, curve:

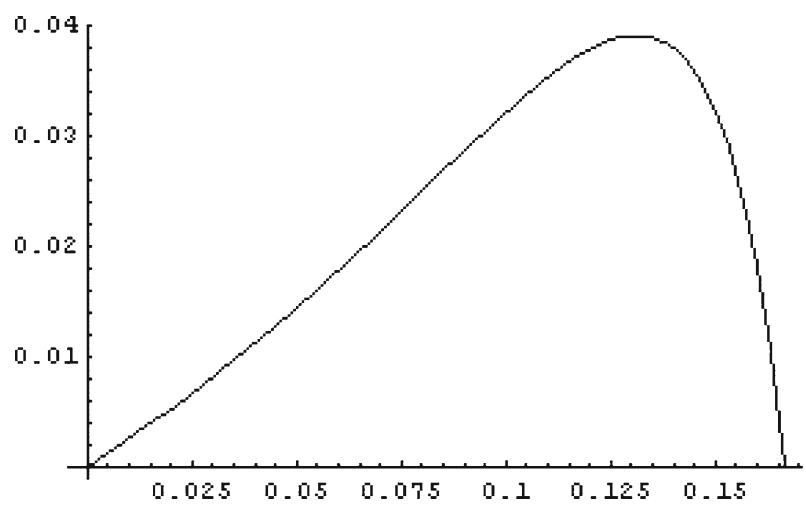

Acknowledgements I like to thank David Atkinson for his stimulating questions and his help in checking and finding proofs. Thanks are also due to Igor Douven and Jeanne Peijnenburg for their suggestions. Finally, thanks to the Netherlands Institute of Advanced Study (NIAS, Wassenaar) where I could complete this paper.

Open Access This article is distributed under the terms of the Creative Commons Attribution Noncommercial License which permits any noncommercial use, distribution, and reproduction in any medium, provided the original author(s) and source are credited.

\section{References}

Atkinson, D. (2010). Confirmation and justification. A commentary on Shogenji's measure. Synthese, doi:10.1007/s11229-009-9696-4. 
Atkinson, D., Peijnenburg, J., \& Kuipers, T. (2009). How to confirm the disconfirmed. On conjunction fallacies and robust confirmation. Philosophy of Science, 76(1), 1-21.

Kuipers, T. (2001). Structures in science. Dordrecht: Kluwer.

Kuipers, T. (to appear). Comparative realism as the best response to antirealism. Invited lecture, XIII-th LMPS-congress, August 9-15, 2007, Beijing. In Clark Glymour, Wang Wei and Dag Westerståhl (Eds.), Logic, methodology and philosophy of science. Proceedings of the thirteenth international congress.

Kuipers, T. (2009). Empirical progress and truth approximation by the 'Hypothetico-probabilistic method'. Erkenntnis, 70(3), 313-330.

Shogenji, T. (2010). The degree of epistemic justification and the conjunction fallacy. Synthese, doi:10. 1007/s11229-009-9699-1. 